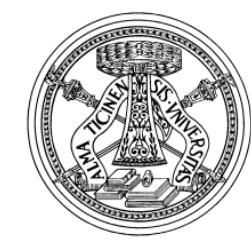

Quaderni di Dipartimento

Endogenous Timing in a Mixed Duopoly

Rabah Amir

(University of Arizona)

Giuseppe De Feo

(Università di Pavia)

\# 162 (02-12)

Dipartimento di economia politica

e metodi quantitativi

Università degli studi di Pavia

Via San Felice, 5

I-27100 Pavia

Febbraio 2012 


\title{
ENDOGENOUS TIMING IN A MIXED DUOPOLY
}

\author{
Rabah $\mathrm{AMIR}^{1}$ and Giuseppe DE FEO ${ }^{2}$
}

May 2011

\begin{abstract}
This paper applies the framework of endogenous timing in games to mixed quantity duopoly, wherein a private - domestic or foreign - firm competes with a public, welfaremaximizing firm. We show that simultaneous play never emerges as a subgame-perfect equilibrium of the extended game, in sharp contrast to private duopoly games. We provide sufficient conditions for the emergence of public and/or private leadership equilibrium. In all cases, private profits and social welfare are higher than under the corresponding Cournot equilibrium. From a methodological viewpoint we make extensive use of the basic results from the theory of supermodular games in order to avoid common extraneous assumptions such as concavity, existence and uniqueness of the different equilibria, whenever possible. Some policy implications are drawn, in particular those relating to the merits of privatization.
\end{abstract}

Keywords and phrases: Mixed markets, endogenous timing, Cournot equilibrium, Stackelberg equilibrium, privatization.

JEL Classification: C72, D43, H42, L13

\footnotetext{
${ }^{1}$ Department of Economics, University of Arizona. E-mail: ramir@eller.arizona.edu.

${ }^{2}$ Dipartimento di Economia Politica e Metodi Quantitativi, Università degli Studi di Pavia and Department of Economics, University of Strathclyde. E-mail: giuseppe.defeo@unipv.it

We wish to thank audiences at CORE, 2007 EARIE conference in Valencia, 2008 ESEM conference in Milano, and 2009 PET conference in Galway. The scientific responsibility is assumed by the authors. The second author gratefully acknowledges financial support from Fondazione "Alma Mater" - Pavia, Progetto "La Governence delle imprese e dei mercati dopo la crisi".
} 


\section{Introduction}

In several important markets public firms compete with a small number of private rivals. Examples include the banking industry (with postal banks in UK, Germany, Italy, New Zealand), as well as TV broadcasting in most of the developed countries. Moreover, health care services and insurance, transportation, energy, overnight delivery (even in the US) are usually provided by state-owned enterprises in competition with private firms. In industrial organization, the term mixed oligopoly has been used to designate such imperfectly competitive markets.

A strand of theoretical literature began to devote closer attention to mixed oligopolies in the 1980s, following a privatization wave that started in some of the most industrialized countries (in particular the U.S. and the U.K.), and soon extended to transition and developing economies. The aim of this literature has been to characterize mixed oligopoly equilibria and to study the welfare effects of privatization by adapting the standard oligopoly models to the presence of welfare-maximizing firms. Results and policy prescriptions turn out to crucially depend on the type of competition assumed (in quantity competition, for example, Cournot or Stackelberg games). In de Fraja and Delbono (1989) it is shown that, if a Stackelberg game with public leadership is played, privatization cannot improve welfare, absent efficiency gains; while on the contrary, under Cournot competition, this may occur. Beato and MasColell (1984) show that welfare may be higher when the public firm is the follower than when it is the leader in a Stackelberg game. ${ }^{1}$ During the last decade greater attention has also been devoted to international mixed oligopolies, in which a domestic public firm competes with foreign private firms. ${ }^{2}$ Again, results and policy prescriptions over privatization depend on the type of competition assumed, either simultaneous-move (Cournot) or sequential-move (Stackelberg) game.

Stemming from the standard analysis of second-best theory (Lipsey and Lancaster, 19561957; Rees, 1984; Bös, 1986), the assumption of public leadership has long been considered rather natural in mixed markets. In fact, claiming the sub-optimality of the marginal-cost pricing, the public firm can optimally depart from this rule by taking into account the reaction of the private firms when maximizing social welfare. This natural assumption as been criticized by Cremer et al. (1989) that instead supported the general plausibility of the (Cournot-) Nash equilibrium in the analysis of oligopolistic markets. Beato and Mas-Colell (1984) shared the idea of a dominant position of the public firm, but questioned the optimality of public leadership. Instead of announcing its output, the public firm can commit to behaving as follower by announcing the marginal-cost pricing rule, if private leadership is preferred to the public leadership equilibrium.

\footnotetext{
${ }^{1}$ See de Fraja and Delbono (1990) and Nett (1993) for a survey of these models.

${ }^{2}$ See for example Fjell and Pal (1996), Pal and White (1998), Fjell and Heywood (2002).
} 
Importantly, in much of the previous literature on public firms, it is tacitly assumed that the public firm can freely choose the type of the game independently of the behavior of private firms. The aim of the present work is to introduce to this literature basic ideas from endogenous timing theory to identify a suitable timing for a mixed duopoly quantity game where a private - domestic or foreign - firm competes with a public, welfare-maximizing firm. To this end, we use the model of endogenous timing with observable delay developed by Hamilton and Slutsky (1990). ${ }^{3}$ In their model, a preplay stage is added to the duopoly game, in which players simultaneously decide whether to move early or late in the basic duopoly game. At the end of this stage, timing decisions are revealed and then the basic game is played according to the announcements: If both choose the same timing, the game is then played with simultaneous moves, while if timing decisions are different, sequential play under perfect information - with the order of moves as decided by the players - takes place. As a consequence, in the subgame perfect equilibrium (SPE) of the extended game, the relevant equilibrium solution for the basic game endogenously emerges. In contrast to the extant literature, in the present setting, neither firm can unilaterally choose the timing of the game, since it is the result of the simultaneous decisions of both firms.

This feature of the model provides one of the arguments supporting the adoption of the endogenous timing game to describe market outcomes in mixed oligopolies. On the one hand, there is no theoretical justification for the assumption that the public firm can choose the timing of the game independently of the private competitors. Since a dominant position can only derive from the ability of credible commitment, there is no reason why one should think that only public firms has such an ability. ${ }^{4}$ On the other hand, the timing decisions of the firms depend on the payoffs in the different simultaneous or sequential games that, in turn, are determined by the primitives of the industry (cost and demand functions). Therefore, the model presented in this paper can account for the emergence of different types of competition in different industries that can be characterized as mixed oligopolies.

This is consistent with some observed facts and empirical findings in mixed markets. For example, the state-owned Norwegian supplier of electricity, Statkraft, behaves as if it were the residual producer in the case of dramatic price change (Magnus and Midttun, 2000). We can interpret this behavior as the announcement by the state-owned firm that it is committed to sustain a certain price level on the market, that is to behave as follower with respect to private competitors that can choose the optimal level of production knowing the credibly announced reaction of Statkraft. In industries such as energy markets, capacity investments can easily work as credible commitments by private firms to behave as leader in a Stackelberg game. In

\footnotetext{
${ }^{3}$ See also Amir (1995) and von Stengel (2010). For a thorough study of Stackelberg leadership when the leader can commit to mixed strategies, see von Stengel and Zamir (2010).

${ }^{4}$ Even more stenuous is the claim that the public follower can unilaterally implement the Stackelberg equilibrium because of its dominant position, as in Beato and Mas-Colell (1984).
} 
general, whenever public firms commit to pursuing market goals such as total quantity, price level or universal service obligations not fulfilled by private competitors, one can interpret such behavior as announcing to "move late", using the simple endogenous timing terminology.

In health care markets, the public provider in countries such as France and Germany is usually considered as a leader when competing with private firms. ${ }^{5}$ The definition of the public firm's performance objective can be understood as a credible commitment to "move early" in order to act as a leader that takes into account what will be produced by the private competitors.

Over the last decade, several papers have applied this framework to particular instances of mixed oligopoly quantity games. Pal (1998) analyses a domestic oligopoly with linear cost and demand functions; Matsumura (2003) focused on international mixed duopoly with convex costs and concave demand; Cornes and Sepahvand (2003) and Sepahvand (2004) consider international mixed duopolies with strictly log-concave demand and strictly convex cost functions. The aim of the present work is to generalize their analysis for the general case of a mixed duopoly (both domestic and international) limiting the assumptions to the mildest conditions needed to ensure existence of equilibria. This approach allows us to identify a general explanation and classification of the results that was not fully provided in previous work on the subject.

We consider all the different cases that can arise according to whether the private competitor is domestic or foreign, and to whether the duopoly game is characterized by strategic complementarity or substitutability. A domestic mixed duopoly differs from an international one since the private firm's profits are not included in the public firm's objective function in the latter case. Our main finding is that Cournot competition never arises as the equilibrium of the mixed duopoly game when both firms are active on the market.

More precisely, we show that when quantities are strategic substitutes for both firms (i.e. best-response correspondences are downward sloping), the Stackelberg equilibria with both private and public leadership arise as the SPE of the endogenous timing game. We then provide sufficient conditions for the emergence of public and/or private leadership Stackelberg equilibria in a comprehensive characterization of the mixed duopoly quantity game. A sufficient condition to have downward sloping best-response correspondence for the private firm is the log-concavity of the (inverse) demand function. For the public firm, the best-response correspondence is always downward sloping in a domestic duopoly, while this property entails convexity of the demand function in an international duopoly (in both cases, these conditions hold true regardless of the cost functions of the two firms).

Our results have to be contrasted with those obtained in the private duopoly framework. Amir and Grilo (1999) show that Cournot solution always emerges via the same endogenous

\footnotetext{
${ }^{5}$ See for example Barros (1995).
} 
timing scheme when quantities are strategic substitutes for both firms, thus giving theoretical support to the general preference for Cournot over Stackelberg games in a private oligopoly setting (thus justifying the rejection of Stackelberg's equilibrium for private duopoly). The main difference between the private and mixed duopoly settings lies in the fact that the public firm's objective is generally increasing in private firm's output, while the contrary is true for private firms. ${ }^{6}$

As a consequence, under strategic substitutability for both firms, the public firm's output as Stackelberg leader is smaller than the one in a simultaneous-move game. In order to induce an increase in the rival's output, the public leader produces less that in any Cournot equilibrium. So, the private firm prefers to be follower than Cournot player and public leadership Pareto dominates any Cournot equilibrium. The same is true for private leadership: The private firm produces more when Stackelberg leader than under Cournot competition and the public firm prefers to be follower than simultaneous player.

When the reaction correspondence of the private firm is increasing while strategic substitutability holds for the public firm, private leadership is the unique SPE of the endogenous timing game in both domestic and international duopoly. ${ }^{7}$ In this case Pareto dominance of private leadership over Cournot competition again holds, while public leadership dominance is no longer true. In fact, in order to have a larger private production with respect to simultaneous-move game, the public leader produces more than under Cournot competition and the private firm's profits are reduced. Then, the private firm always prefers to move early and the best timing response of the public firm is to move late.

In an international mixed duopoly a third case may occur. If the demand function is concave, the best-response correspondence of the public firm is increasing while the private firm's is decreasing. As a result, the Pareto dominance of the public leadership over Cournot competition holds, while the private leadership solution does not Pareto dominate the simultaneous equilibria. The latter is due to the fact that the private firm reduces its production as a Stackelberg leader relative to the Cournot solution. Then, the public firm always prefers to move early in order to avoid private leadership, and public leadership emerges as the unique SPE of the endogenous timing game.

From a methodological point of view, we make extensive use of the basic results of the theory of supermodular games. ${ }^{8}$ These are also called games with strategic complementarities and are characterized by the monotonicity of the best responses to rival's action. The

\footnotetext{
${ }^{6}$ As we will see, the public firm's objective is always increasing in the rival's output in an international mixed duopoly, while in a domestic duopoly this is true when the price is larger than the rival's marginal cost.

${ }^{7} \mathrm{~A}$ sufficient condition is log-convexity of demand function and zero production costs for the private firm.

${ }^{8}$ This theory was initiated by Topkis $(1978,1979)$ and further developed by Vives (1990), Milgrom and Roberts (1990), and Milgrom and Shannon (1994). We base our analysis on the main results of Novshek (1985) and Amir (1996a) on the private Cournot duopoly.
} 
advantages of using this approach are that no concavity assumptions are needed and nevertheless existence of pure-strategy Cournot equilibria is guaranteed. Moreover we can deal with multiplicity of equilibria since they can be preference-ranked for both private and public firms.

The present paper is organized as follows. Section 2 describes the model. Section 3 summarizes the basic mechanism used for endogenous timing and the basic concepts of the supermodularity approach. Section 4 contains the analysis of an international mixed duopoly, while Section 5 provides the results for a domestic mixed duopoly. Section 6 briefly concludes. In the Appendix some intermediate results are provided together with the omitted proofs of the results of the paper.

\section{The model}

In this paper we consider a mixed oligopoly market in which one private, profit maximizing firm competes with a public firm whose objective is to maximize domestic social welfare. The main question under investigation is whether Stackelberg equilibrium might constitute a more natural solution concept than standard (simultaneous-move) Cournot-Nash equilibrium for such markets. We elaborate on this central issue in full generality, allowing for separate analysis of two possible scenarios depending on whether the private firm is foreign or domestic, and for different assumptions on market demand and firms' cost functions.

The two firms, labeled 1 (private firm) and 0 (public firm), compete in quantities and their products are homogeneous (or perfect substitutes). The market inverse demand function is $P(\cdot)$, and the two cost functions are $C_{1}\left(q_{1}\right)$ and $C_{0}\left(q_{0}\right)$. The two firms' profit functions are then

$$
\Pi_{1}\left(q_{0}, q_{1}\right)=q_{1} P\left(q_{0}+q_{1}\right)-C_{1}\left(q_{1}\right)
$$

and

$$
\Pi_{0}\left(q_{0}, q_{1}\right)=q_{0} P\left(q_{0}+q_{1}\right)-C_{0}\left(q_{0}\right)
$$

Consumer surplus is

$$
C S\left(q_{0}, q_{1}\right)=\int_{0}^{q_{0}+q_{1}} P(z) d z-\left(q_{0}+q_{1}\right) P\left(q_{0}+q_{1}\right) .
$$

Since the public firm's objective function is social welfare, it depends on whether the private firm is domestic or foreign. We shall analyze the two cases separately. If the private firm is domestic, then the public firm maximizes

$$
\begin{aligned}
W^{d}\left(q_{0}, q_{1}\right) & \triangleq C S\left(q_{0}, q_{1}\right)+\Pi_{0}\left(q_{0}, q_{1}\right)+\Pi_{1}\left(q_{0}, q_{1}\right) \\
& =\int_{0}^{q_{0}+q_{1}} P(z) d z-C_{0}\left(q_{0}\right)-C_{1}\left(q_{1}\right) .
\end{aligned}
$$


If the private firm is foreign, the public firm's objective is

$$
\begin{aligned}
W^{f}\left(q_{0}, q_{1}\right) & \triangleq C S\left(q_{0}, q_{1}\right)+\Pi_{0}\left(q_{0}, q_{1}\right) \\
& =\int_{0}^{q_{0}+q_{1}} P(z) d z-q_{1} P\left(q_{0}+q_{1}\right)-C_{0}\left(q_{0}\right) .
\end{aligned}
$$

As usual, a mixed-duopoly Cournot equilibrium is defined as a pair of (nonnegative) quantities $\left(q_{0}^{c}, q_{1}^{c}\right)$ such that

$$
W^{i}\left(q_{0}^{c}, q_{1}^{c}\right) \geq W^{i}\left(q_{0}, q_{1}^{c}\right) \quad \forall q_{1} \geq 0 ; i=d, f
$$

and

$$
\Pi_{1}\left(q_{0}^{c}, q_{1}^{c}\right) \geq \Pi_{1}\left(q_{0}^{c}, q_{1}\right) \quad \forall q_{0} \geq 0
$$

Thus, in any mixed-duopoly Cournot equilibrium, each firm optimally replies to the action of the rival and so $\left(q_{0}^{c}, q_{1}^{c}\right)$ must lie on the best-response correspondences of both firms. The latter are defined in the standard way:

$$
\begin{aligned}
& r_{0}\left(q_{1}\right) \triangleq \arg \max _{q_{0} \geq 0} W^{i}\left(q_{0}, q_{1}\right) \quad i=d, f \\
& r_{1}\left(q_{0}\right) \triangleq \arg \max _{q_{1} \geq 0} \Pi_{1}\left(q_{0}, q_{1}\right) .
\end{aligned}
$$

We denote the set of (mixed-duopoly) Nash-Cournot equilibria by $\mathbf{N}$.

A Stackelberg equilibrium of this game corresponds to the subgame perfect equilibrium (SPE) of a two stage game of perfect information in which the second mover (follower) chooses an action after having observed the action of the first mover (leader). A strategy for the leader is to pick a quantity $q_{i} \geq 0$ and a strategy for the follower is $\rho_{j}\left(q_{i}\right)$, where $\rho_{j}(\cdot)$ is a mapping from the domain of $q_{i}$ to the domain of $q_{j}$. Assuming that firm 0 is the leader, a Stackelberg equilibrium of this mixed duopoly game with public leadership is then a pair $\left(q_{0}^{l}, \rho_{1}^{*}(\cdot)\right)$ such that

$$
W^{i}\left(q_{0}^{l}, \rho_{1}^{*}\left(q_{0}^{l}\right)\right) \geq W^{i}\left(q_{0}, \rho_{1}^{*}\left(q_{0}\right)\right) \quad \forall q_{0} \geq 0 ; i=d, f \text { and }
$$

and

$$
\Pi_{1}\left(q_{0}^{l}, \rho_{1}^{*}\left(q_{0}^{l}\right)\right) \geq \Pi_{1}\left(q_{0}^{l}, q_{1}\right) \forall q_{1} \geq 0 .
$$

A Stackelberg equilibrium with private leadership is a pair $\left(\rho_{0}^{*}(\cdot), q_{1}^{l}\right)$ such that

$$
\Pi_{1}\left(\rho_{0}^{*}\left(q_{1}^{l}\right), q_{1}^{l}\right) \geq \Pi_{1}\left(\rho_{0}^{*}\left(q_{1}\right), q_{1}\right) \quad \forall q_{1} \geq 0
$$

and

$$
W^{i}\left(\rho_{0}^{*}\left(q_{1}^{l}\right), q_{1}^{l}\right) \geq W^{i}\left(q_{0}, q_{1}^{l}\right) \forall q_{0} \geq 0 ; i=d, f .
$$

In other words, a Stackelberg equilibrium imposes that: (i) the strategy of the second mover be a single-valued selection from its best-response correspondence; and (ii) the first 
mover choose an action that maximizes its objective function given the anticipation of the rival's reaction.

A Stackelberg equilibrium with public leadership is a pair $\left(q_{0}^{l}, q_{1}^{f}\right)$ with $q_{1}^{f} \in r_{1}\left(q_{0}^{l}\right)$ and $q_{0}^{l} \in \arg \max _{q_{0} \geq 0} W^{i}\left(q_{0}, r_{1}\left(q_{0}\right)\right)$, while a Stackelberg equilibrium with private leadership is a pair $\left(q_{0}^{f}, q_{1}^{l}\right)$ with $q_{0}^{f} \in r_{0}\left(q_{1}^{l}\right)$ and $q_{1}^{l} \in \arg \max _{q_{1} \geq 0} \Pi_{1}\left(r_{0}\left(q_{1}\right), q_{1}\right)$.

We denote the set of Stackelberg equilibria with public and private leadership by $S_{0}$ and $S_{1}$ respectively.

Since the leader's optimal choice results from a pure optimization problem, all the points in $S_{i}$ must yield the same payoff to the leader (firm i). It follows that the Stackelberg solution is generically unique (i.e., multiple solutions would turn into a unique outcome upon a slight perturbation of the primitives of the duopoly).

Throughout the paper we assume the following very general conditions.

Assumption 1 The inverse demand function $P(\cdot)$ is twice continuously differentiable and positive (in the relevant range) with $P^{\prime}(\cdot)<0$ and $\lim _{x \rightarrow \infty} P(x)=0$.

Assumption 2 The cost functions $C_{0}(\cdot)$ and $C_{1}(\cdot)$ are strictly increasing and twice continuously differentiable with $C_{i}(0)=0 \quad \forall i=0,1$.

Under these assumptions both firms' action sets are compact since the firms never produce quantities larger than some upper-bound. This is due to the fact that price is strictly decreasing to 0 and marginal costs are strictly positive. As a consequence, there exists a $k_{i}$ such that the outputs $\left(k_{i}, \infty\right)$ are strictly dominated strategies for firm $i=0,1$.

\section{Endogenous timing: Some basics}

As this paper brings together two different methodologies, this section provides a self-contained but simple summary of the notions and results from endogenous timing theory, and from supermodular optimization and games, that are needed in this paper.

\subsection{Endogenous timing}

The aim of this paper is to identify the appropriate sequencing of moves in a mixed duopoly game. We investigate how the choice between simultaneous (Cournot) and sequential (Stackelberg) games and the assignment of leader and follower roles in the latter case arise endogenously. To this end, we adopt the simple model of extended game with observable delay due to Hamilton and Slutsky (1990) (also see Amir, 1995). 


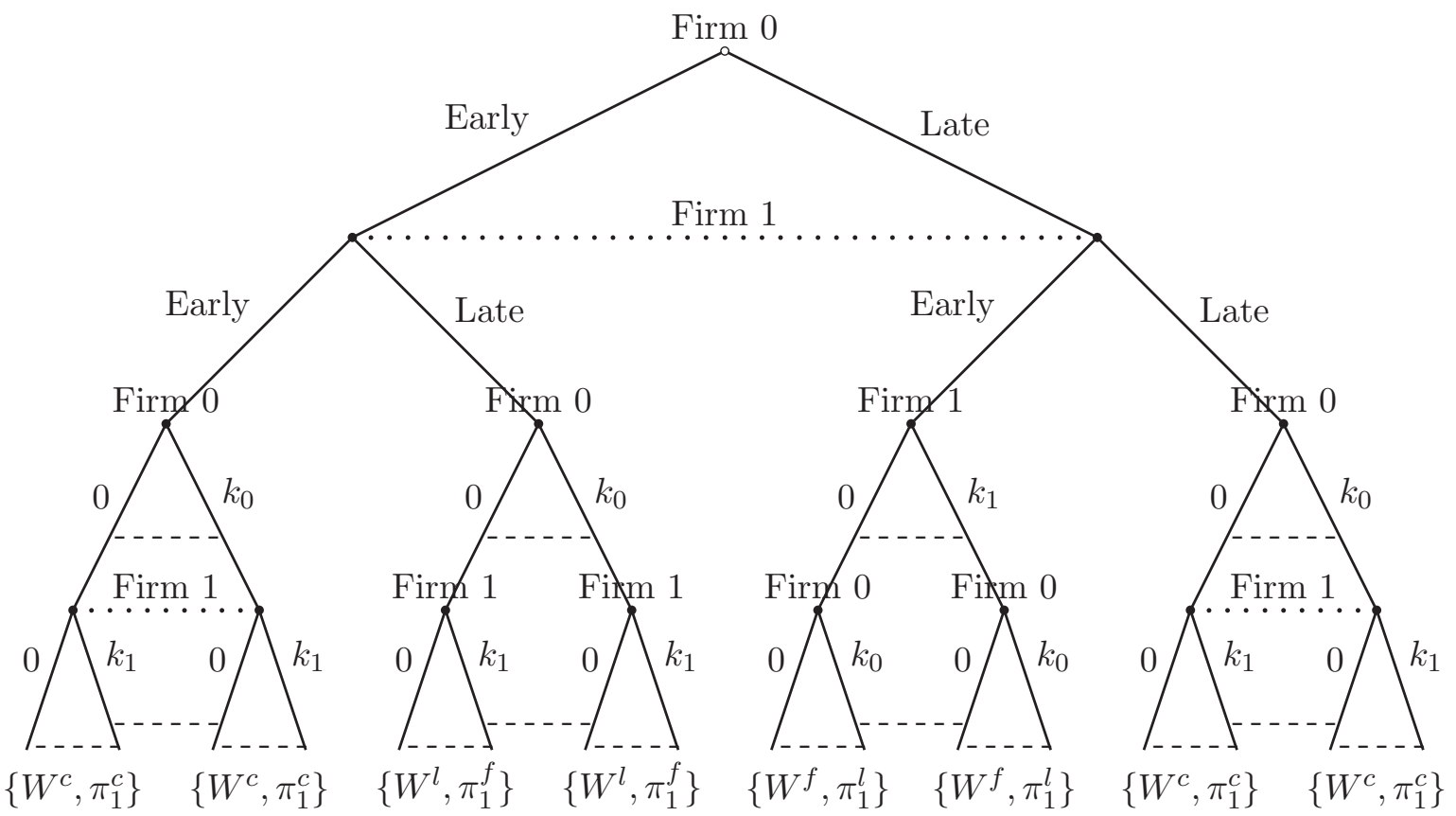

Figure 1: The extensive form of the Hamilton and Slutsky (1990)'s model extended game with observable delay.

In this model, a preplay stage is added to the duopoly game. At this stage players simultaneously decide whether to move early or late in the "basic duopoly game". ${ }^{9}$ At the end of this stage, timing decisions are revealed and the basic game is then played according to these announcements: if both players choose the same timing, simultaneous (Cournot) game is played; while, if timing decisions are different, sequential play under perfect information with the order of moves as decided by the players - occurs. As a consequence, the subgame perfect equilibrium of the extended game endogenously determines the relevant equilibrium concept for the basic game. It should be emphasized that a player cannot unilaterally choose to be a leader or a follower. However, he may elect not to be a follower simply by deciding to move early in the preplay stage, or not to be a leader by deciding to move late.

In Figure 3.1 the game tree of the extended game with observable delay of Hamilton and Slutsky (1990) is depicted.

The following Proposition summarizes the results of the Hamilton and Slutsky (1990)

\footnotetext{
${ }^{9}$ What the literature on endogenous timing refers to as "basic game" actually consists of three distinct games, depending on whether play is simultaneous or sequential, and in the latter case on whether player 0 or 1 is the first-mover. With this point clarified, we continue to abuse terminology by referring to these three games collectively as the "basic game".
} 
model. It characterizes the pure-strategy subgame-perfect equilibria (henceforth, SPE) of the extended game, that is a pair of timing announcements and the equilibrium quantities in the basic game. For the time being, we have to assume that leadership payoffs are strictly larger than any mixed-duopoly Cournot payoff and that all equilibria exist. In the next sections we define conditions for existence of equilibria in the two cases of domestic and foreign private firm, and show that the leader's payoffs are indeed always larger than the corresponding Nash payoffs under our assumptions. ${ }^{10}$

A central result for the outcome of this endogenous timing scheme, which is repeatedly invoked in the upcoming analysis is as follows (for a proof, see Hamilton and Slutsky, 1990). For the basic game, let $N$ denote respectively the set of (simultaneous-move) pure-strategy Nash equilibria, $S_{i}$ the set of Stackelberg equilibria with firm $i$ as leader, $i=0,1$, respectively. Let $E$ denote the set of subgame-perfect equilibria of the (endogenous-timing) extended game.

Proposition 3 Consider a two-player game in which Cournot-Nash and Stackelberg equilibria with both order of moves exist. Assume that both firms strictly prefers the leader payoff to any simultaneous play playoff. Then:

(i) if each firm's Stackelberg follower payoff is smaller than its least preferred simultaneous play payoff, then both firms decide to move early and Cournot equilibrium is the unique $S P E$ of the extended game, i.e. $E=N$.

(ii) if each firm's Stackelberg follower payoff is strictly larger than its most preferred simultaneous play payoff, then sequential play with either order of move are the only (purestrategy) SPEs of the extended game, i.e., $E=S_{0} \cup S_{1}$.

(iii) if firm i's Stackelberg follower payoff is strictly larger than its most preferred simultaneous play payoff and if firm j's Stackelberg follower payoff is strictly smaller than its least preferred Cournot payoff, then firm $j$ moves early, firm $i$ moves late and $j$-leadership is the unique SPE of the extended game, i.e. i.e., $E=S_{j}$.

In a nutshell, this result says that a particular Stackelberg equilibrium will prevail if the corresponding follower prefers his payoff then to what he would get at the Cournot-Nash equilibrium. Since the leader always has such a preference, a Stackelberg outcome will prevail if and only if it Pareto dominates a Nash outcome. If the same preference does not hold for either player, then the outcome will be Cournot-Nash equilibrium.

\footnotetext{
${ }^{10}$ This fact is always true when the reaction correspondences are continuous functions, but as the present setting allows for discontinuities, the same result requires proof.
} 


\subsection{Supermodular optimization and games}

As much of the analysis of the present paper rests crucially on some basic results from the theory of supermodular games, we now provide a brief overview of the needed notions (see Topkis, 1978, 1998, for more details).

A function $F: \mathbb{R}_{+}^{2} \rightarrow \mathbb{R}$ has strict increasing differences (decreasing differences) if, $\forall x^{\prime} \geq$ $x, y^{\prime} \geq y$

$$
F\left(x^{\prime}, y^{\prime}\right)-F\left(x, y^{\prime}\right)>(<) F\left(x^{\prime}, y\right)-F(x, y)
$$

$F(x, y)$ has the strict single-crossing property or $S C P($ dual $S C P)$ in $(x ; y)$ if $\forall x^{\prime} \geq x, y^{\prime} \geq y$

$$
F\left(x^{\prime}, y^{\prime}\right)-F\left(x, y^{\prime}\right)>(<) 0 \Longleftarrow F\left(x^{\prime}, y\right)-F(x, y)>(<) 0
$$

Topkis's Theorem (1978) states that if $F(x, y)$ satisfies increasing differences (decreasing differences), then the correspondence $x^{*}(y) \triangleq \arg \max _{x \geq 0} F(x, y)$ has the property that all its selections are increasing (decreasing) in $y$. Milgrom and Shannon (1994) showed that the same conclusion holds when $F(x, y)$ satisfies only the SCP in $(x, y)^{11}$

In the present paper, we make use of a stronger version of these results: If $\frac{\partial F(x, y)}{\partial x}$ is strictly increasing (decreasing) in $y$, then every selection of $x^{*}$ is strictly increasing (strictly decreasing) in $y$ (Amir (1996b, Theorem 3) and Topkis (1998, p. 79)).

It is well-known that unambiguous endogenous timing outcomes for a two-player game are predicated on each of the best responses being monotonic (increasing or decreasing) and on each payoff function satisfying the uni-signed externality property (positive or negative): See Hamilton and Slutsky (1990) and Amir (1995). To deal with these properties, we need to define the corresponding classes of games.

A game is supermodular (submodular), or equivalently has strategic complementarities (substitutabilities), if each payoff function has the SCP (dual SCP). The key property of such games is that the associated best response mapping has maximal and minimal selections that are increasing (decreasing) functions, a direct consequence of Topkis's Theorem. We will also consider some hybrid-complementarity games, characterized by the SCP for one payoff function and the dual SCP for the other.

A game has positive (negative) externalities if each payoff function is increasing (decreasing) in rival's action. We will also consider some hybrid-externality games, characterized by uni-signed externalities, positive for one payoff function and negative for the other.

\footnotetext{
${ }^{11}$ Note that IDP is a cardinal property of the function $F$, while SCP is an ordinal property.
} 


\section{Endogenous timing in mixed duopoly with a foreign private firm}

In this section we consider the case in which the private firm is foreign, so that its profits are not included in the objective function of the public firm, as defined in equation (2). As noted earlier, endogenous timing outcomes depend crucially on the signs of the payoff externalities and the slopes of the reaction curves of the basic game. When the private firm is foreign, there are three separate sign configurations that lead to different endogenous timing outcomes. All three configurations share the central result that Cournot equilibrium (i.e, simultaneous play in the mixed duopoly) never arises in any SPE of the endogenous timing game. In other words, the outcome is always Stackelberg leadership but the identity of the leader varies across the three cases.

We begin by observing that the payoff externalities are always unambiguously pinned down by the fact that demand is strictly decreasing: Indeed, the private firm's profit is strictly decreasing in the public firm's output, but welfare is strictly increasing in the private firm's output since

$$
\begin{array}{cl}
\frac{\partial \Pi_{1}\left(q_{0}, q_{1}\right)}{\partial q_{0}}=P^{\prime}\left(q_{0}+q_{1}\right) q_{1}<0 & \forall q_{0}, q_{1} \geq 0 \\
\frac{\partial W^{f}\left(q_{0}, q_{1}\right)}{\partial q_{1}}=-q_{1} P^{\prime}\left(q_{0}+q_{1}\right)>0 & \forall q_{0}, q_{1} \geq 0 .
\end{array}
$$

As to the sign of the slopes of the reaction curves of the basic game, we now provide sufficient conditions for each of them to increase or decrease in the next two intermediate results.

Lemma 4 In addition to Assumptions 1 and 2,

(a) Assume that $P^{\prime \prime}(\cdot)>0$. Then any selection of the public firm's best-response correspondence $r_{0}\left(q_{1}\right)$ is strictly decreasing whenever interior.

(b) Assume that $P^{\prime \prime}(\cdot)<0$. Then any selection of $r_{0}\left(q_{1}\right)$ is strictly increasing whenever interior.

Lemma 5 In addition to Assumptions 1 and 2:

(a) Assume that $P(\cdot)$ is strongly log-concave. i.e. that ${ }^{12}$

$$
P(x) P^{\prime \prime}(x)-P^{\prime 2}(x)<0, \quad \forall x>0 .
$$

Then, every selection of the private firm's best-response correspondence $r_{1}\left(q_{0}\right)$ is strictly decreasing whenever interior.

\footnotetext{
${ }^{12}$ An alternative assumption that yields decreasing reaction curves is $P^{\prime}(x)+x P^{\prime \prime}(x)<0$ (Novshek, 1985).
} 
(b) Assume that $C_{1}(\cdot) \equiv 0$ and $P(\cdot)$ is strongly log-convex everywhere, i.e.

$$
P(x) P^{\prime \prime}(x)-P^{\prime 2}(x)>0, \quad \forall x>0 .
$$

Then, every selection of the best-response correspondence $r_{1}\left(q_{0}\right)$ is strictly increasing whenever interior.

As discussed in detail in Amir (1996), the presence of significant variable or fixed costs is not compatible with globally increasing reaction curves for private firms in a Cournot setting (unless the inverse demand curve remains above the average cost curve even for arbitrarily large outputs, an unrealistic case). ${ }^{13}$

Of the four possible cases where the two reactions curces are monotonic (upward or downward), the case in which both are increasing is ruled out by the above lemmas. Indeed, by Lemma $5(\mathrm{~b}), P^{\prime \prime}(\cdot)>0$ is a necessary condition to have a strictly increasing private firm's best response, but $P^{\prime \prime}(\cdot)>0$ implies that the public firm's best response is downward sloping.

Throughout the paper, we allow the basic game to have multiple pure-strategy Nash equilibria, i.e. $N$ need not be a singleton. However, we treat $S_{0}$ and $S_{1}$ as singletons, since it can be shown that this is generically the case. ${ }^{14}$

The following Theorem characterizes the SPE of the extended game, thus determining clear-cut endogenous timing, for the case where the mixed duopoly is a game of strict strategic substitutes (for both firms), positive externality for the public firm and negative externality for the private firm. Under the assumptions of this Theorem, the mixed-duopoly quantity game is a supermodular game, which implies that the set $N$ of pure strategy mixed-duopoly Cournot equilibria is nonempty. ${ }^{15}$ Under the same assumptions, Stackelberg equilibria with either public or private leadership exist and the set $S_{0}$ and $S_{1}$ are nonempty. ${ }^{16}$

Theorem 6 Assume that $P(\cdot) P^{\prime \prime}(\cdot)-P^{\prime 2}(\cdot)<0$ but $P^{\prime \prime}(\cdot)>0$. Then Stackelberg equilibria with either order of moves are the only SPE of the endogenous timing game. In other words, $E=S_{1} \times S_{2}$.

\footnotetext{
${ }^{13}$ On the other hand, the presence of relatively small variable or fixed costs is consistent with an increasing reaction curve over a range of rival's outputs that may be large enough to constitute the relevant range for the analysis at hand. For simplicity, we simply assume zero costs, so that the upward monotonicity of the reaction curve is global.

${ }^{14}$ In other words, the case in which the leader's optimization problem has two or more global optima is non-generic.

${ }^{15}$ Following Vives (1990), reversing the natural order of the public firm's action set, the game becomes supermodular with effective strategy set $\left[0, k_{0}\right] \times\left[0, k_{1}\right]$. By Tarski's fixed point theorem the set $N$ is not empty.

${ }^{16}$ Note that the effective action spaces are compact and the payoff functions are jointly continuous, so that the follower's best response correspondence has a closed graph. Then, as proved by Hellwig and Leininger (1987), Stackelberg equilibria exist.
} 
This result requires $P(\cdot)$ to be both strongly convex and strongly log-concave, which are clearly mutually compatible conditions. A class of examples is $P(x)=e^{-x^{\alpha}}$, with $\alpha>1$.

The following direct consequence is worth noting, even though it follows at once from the mechanism invoked here for endogenous timing (in other words, its proof indeed forms part of the proof of the previous Theorem).

Corollary 7 At either of the two Stackelberg equilibria, social welfare and private profit are higher than at the corresponding (simultaneous-move) Nash equilibrium, i.e. welfare is higher at $S_{0}$ or $S_{1}$ than at $N$.

This result is depicted in Figure 2. From Proposition 3 is clear that Stackelberg play arises in the equilibrium of the endogenous timing game only if it Pareto dominates the Cournot equilibrium. In the case discussed in Theorem 6 both private and public leadership equilibria Pareto dominate the Cournot outcome and therefore are the SPE of the endogenous timing game.

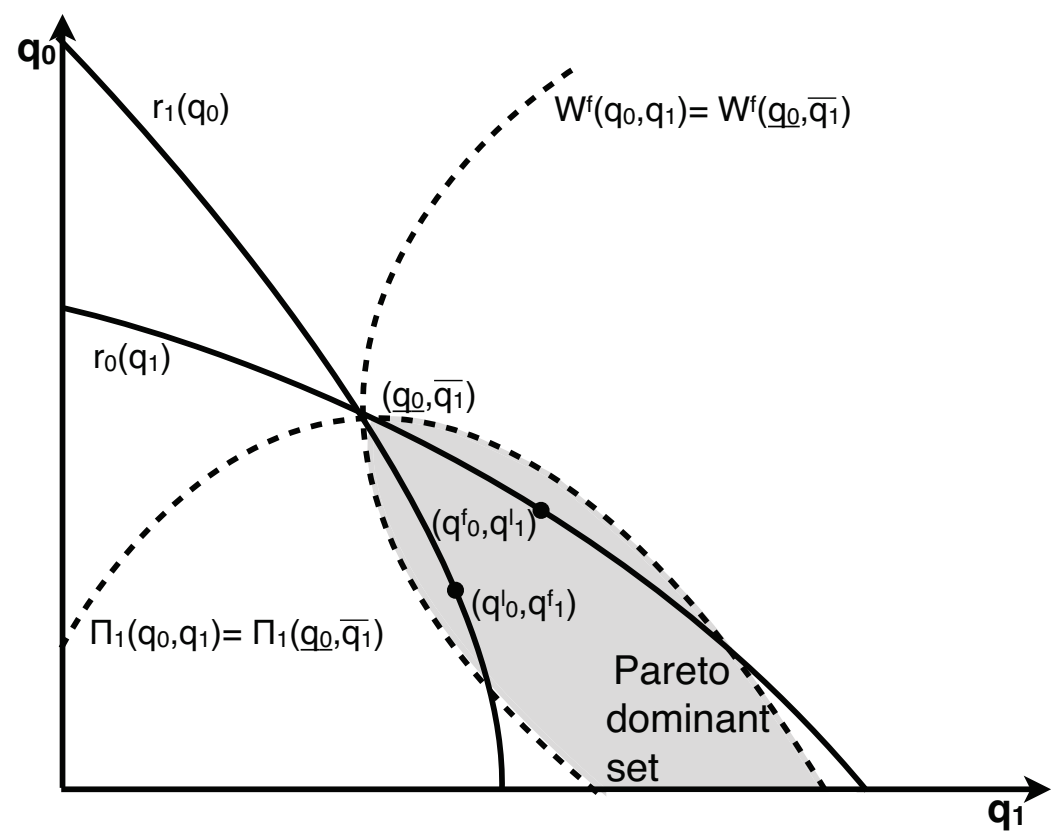

Figure 2: Both Stackelberg equilibria Pareto dominates the Cournot equilibria

The following Remark discusses the only possible boundary solution, which we rule out only for the sake of avoiding making uninteresting statements about the set $E$ of endogenous timings.

Remark 8 We are tacitly assuming that the Pareto dominant Cournot equilibrium, $\left(\underline{q}_{0}, \bar{q}_{1}\right)$, is not on the boundary, i.e., such that $\underline{q}_{0}=0$. If $\underline{q}_{0}$ were ever equal to 0 , it would mean that 
a monopolist solution prevails as a Cournot equilibrium of the basic game, in which case the Cournot equilibrium would also coincide with both Stackelberg equilibria, and would thus also be an SPE of the endogenous timing game. We rule out this uninteresting case with a tacit assumption of interiority of $\left(\underline{q}_{0}, \bar{q}_{1}\right)$. Similar tacit interiority assumptions are maintained in what follows.

The next Theorem analyzes the case in which the private firm's reaction correspondence is increasing in the rival's output, while the public firm's is still downward-sloping. Here we cannot invoke the results of the theory of supermodular games, since the two reaction correspondences slope in opposite directions, implying that it is not possible to re-order action sets in such a way that both reaction correspondences slope upward. As a consequence, to guarantee existence of Cournot equilibria, we need to revert to the standard approach for establishing existence of pure-strategy Cournot equilibrium, which requires strict quasiconcavity of each firm's objective function in own output to ensure single-valuedness and continuity of the firms' reaction functions. This is done via the sufficient conditions stated in the following result.

Lemma 9 Under the assumptions of point (b) in Lemma 5, the following hold:

(a) The private firm's profit function is strictly quasi-concave in own output if $1 / P(\cdot)$ is a strictly convex function, i.e. if

$$
P(\cdot) P^{\prime \prime}(\cdot)-2\left(P^{\prime}\right)^{2}(\cdot)<0
$$

(b) The public firm's objective function is strictly concave in own output if

$$
P^{\prime}\left(q_{0}+q_{1}\right)-C_{0}^{\prime \prime}\left(q_{0}\right)<0, \forall q_{0}, q_{1} \geq 0 .
$$

Proof. The proof of part (a) is given in Amir (1996a), while the proof of part (b) follows directly from

$$
\frac{\partial^{2} W}{\partial q_{0}^{2}}=\left(P^{\prime}-C_{0}^{\prime \prime}\right)-q_{1} P^{\prime \prime}<0
$$

since $P^{\prime \prime}>0$ by log-convexity.

The following Theorem characterizes the SPE of the extended game, thus determining clear-cut endogenous timing, for the case where the mixed duopoly is a game of strategic complements for the private firm and strategic substitutes for the public firm, positive externality for the public firm and negative externality for the private firm. Since the monotonicity structure of hybrid-complementarity games does not guarantee existence of pure-strategy Nash equilibria, again concavity-type assumptions are needed to ensure existence via the continuity of the best response functions. 
Theorem 10 Assume that $C_{1}(\cdot) \equiv 0, P(\cdot) P^{\prime \prime}(\cdot)-P^{\prime 2}(\cdot)>0$, and conditions (7)-(8) hold. Then, private leadership emerges as the unique SPE of the extended game.

In this case again, it is worth observing a direct consequence of this result is that equilibrium social welfare and private profit are higher under private leadership than under simultaneous moves, as it is clear from Figure 3.

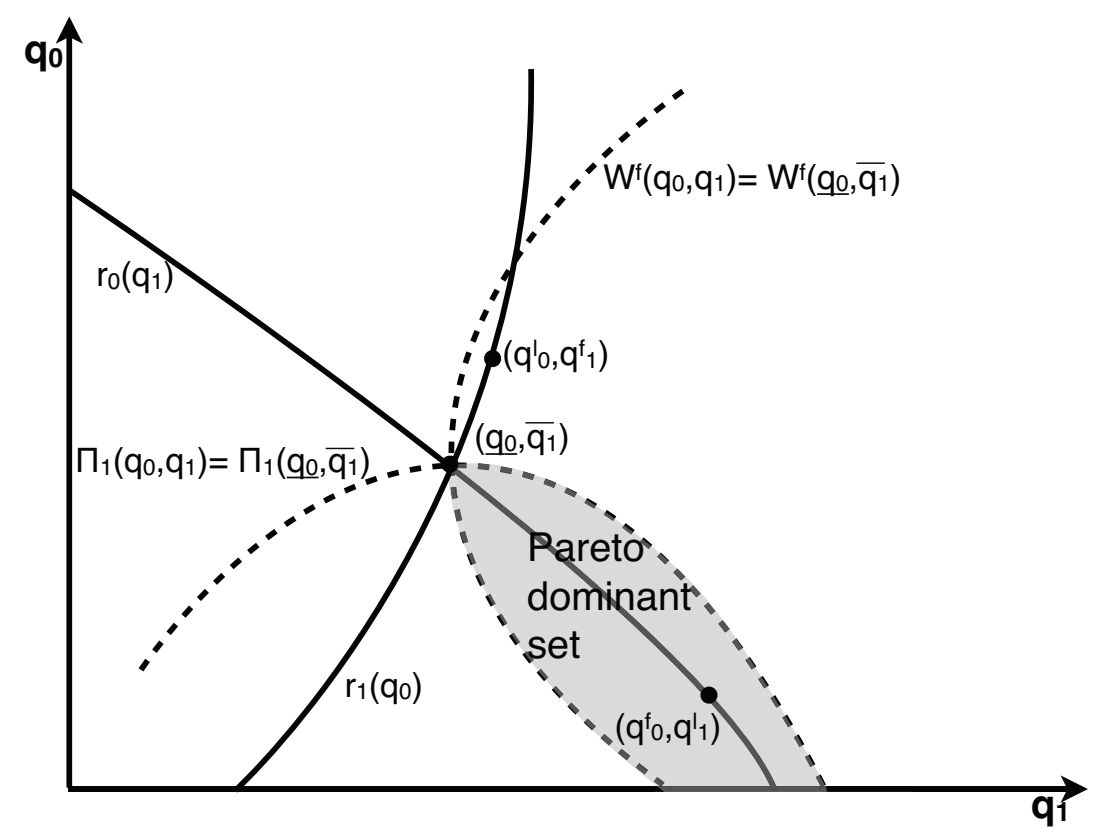

Figure 3: Private Leadership equilibrium Pareto dominates the Cournot equilibria, while public leadership does not and therefore only the first arises in the SPE of the endogenous timing game.

The following Theorem characterizes the SPE of the extended game in the third possible configuration, the case where the mixed duopoly is a game of strategic substitutes for the private firm and strategic complements for the public firm, along with positive externality for the public firm and negative externality for the private firm. Since the monotonicity structure of hybrid-complementarity games does not guarantee existence of pure-strategy Nash equilibria, some concavity-type assumptions are needed to ensure continuous best response functions.

Theorem 11 Assume that $P^{\prime \prime}(\cdot)<0$, and conditions (7)-(8) hold. Then public leadership always emerges as the unique SPE of the endogenous timing game.

Once more, it follows that equilibrium social welfare and private profit are higher under public leadership than under simultaneous moves as shown in Figure 4. 


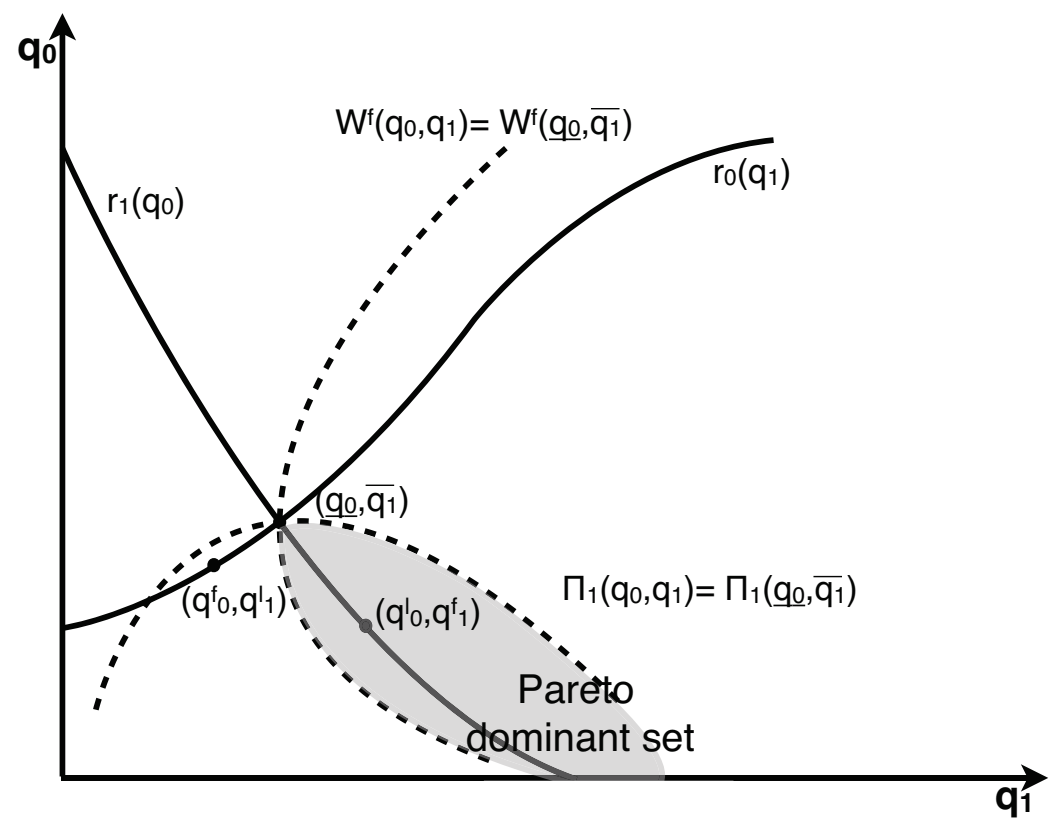

Figure 4: Public leadership equilibrium Pareto dominates the Cournot equilibria, while private leadership does not. Only the former arises in the endogenous timing equilibrium.

\section{Endogenous timing in mixed duopoly with a domestic pri- vate firm}

In this section we consider the case in which the private firm is domestic, so that a public firm maximizing social welfare includes private profits in its objective function, as defined in equation (1). As in the previous setting, we prove that Cournot equilibrium never arises in any SPE of the endogenous timing game ${ }^{17}$. However, in contrast to the case of a foreign private firm, public leadership cannot arise as a SPE of the endogenous timing scheme at hand.

As before, we begin with the signs of the payoff externalities. While the private firm's profits are strictly decreasing in the public firm's quantity (see (5)), welfare is a priori nonmonotonic in the output of the private firm. Nonetheless, as long as price is above the private firm's marginal cost, welfare is increasing in the private firm's output, since

$$
\frac{\partial W^{d}\left(q_{0}, q_{1}\right)}{\partial q_{1}}=P\left(q_{0}+q_{1}\right)-C_{1}^{\prime}\left(q_{1}\right) .
$$

In the following Lemmas we state sufficient conditions for monotonicity of best responses when the private firm is domestic.

\footnotetext{
${ }^{17}$ As before, this conclusion assumes that Cournot equilibrium does not coincide with both Stackelberg equilibria. The latter possibility may occur only on the boundary, when a monopoly solution arises.
} 
Lemma 12 Under Assumptions 1 and 2, any selection of the public firm's best-response correspondence $r_{0}\left(q_{1}\right)$ is strictly decreasing for every $q_{1} \geq 0$ such that $r_{0}\left(q_{1}\right)>0$.

Thus, in contrast to the case of an international mixed duopoly, the public firm's objective function is always submodular here. In what follows we first characterize the case in which the best-response correspondences are decreasing for both firms. As in the previous Section 4, this is a sufficient condition for the game to be supermodular (via the reversal of the order on one of the players' action set), so that existence of mixed-duopoly Cournot and Stackelberg equilibria is guaranteed. The following Theorem characterizes the SPE of the extended game when public and private quantities are strategic substitutes for both firms.

Theorem 13 Assume that $P(\cdot) P^{\prime \prime}(\cdot)-P^{\prime 2}(\cdot)<0$, and that the public firm's cost function $C_{0}(\cdot)$ is convex. Then, Stackelberg equilibria with either order of moves are the only SPEs of the endogenous timing game.

The intuition for this result is as follows. If the public firm is the leader, it produces a lower quantity than in any mixed-duopoly Cournot equilibrium (point (ii) in Lemma 19). The reason is that in any Cournot equilibrium the public firm does not take into account the strategic (negative) effects of its action on the private firm's production. So, when this effect is taken into account, the public leader reduces its quantity, and the private firm produces more than in any Cournot equilibrium. As a result, private profits are larger under public leadership than under simultaneous-move competition.

When the private firm acts as leader, it increases its quantity with respect to any mixedduopoly Cournot equilibrium (point (i) in Lemma 19). In fact, it internalizes the strategic (negative) effects of its action on the rival's production and can increase profits by increasing its own output. The public firm prefers to be the follower than to play simultaneously because the variation in welfare has the same sign and larger magnitude than the variation in private firm's profits, as long as we compare two points on the public firm's reaction correspondence.

As was the case with a foreign firm, a direct corollary of this Theorem is that, at either of the two Stackelberg equilibria, social welfare and private profit are higher than at the corresponding (simultaneous-move) Nash equilibrium, i.e. welfare is higher at $S_{0}$ or $S_{1}$ than at $N$.

The next Theorem analyzes the case in which the private firm's best-response correspondence is increasing in the rival's output. As in the previous Section, the game is not supermodular. We need again to assume quasi-concavity of welfare in public firm's quantity.

Theorem 14 Assume that $C_{1}(\cdot) \equiv 0, P(\cdot) P^{\prime \prime}(\cdot)-P^{\prime 2}(\cdot)>0$, but that $P(\cdot) P^{\prime \prime}(\cdot)-2\left(P^{\prime}\right)^{2}(\cdot)<$ 0 . Assume also that the public firm's cost function $C_{0}(\cdot)$ is convex. Then $r_{0}($.$) and r_{1}($.$) are$ 
single-valued continuous functions that are strictly decreasing and strictly increasing, respectively. Then, private leadership always emerges as the unique SPE of the extended game.

In this case, differently from the one analyzed in Theorem 13, the strategic effect of public firm's action on private firm's production is positive. So, taking into account this effect, the public leader produces more than at the Cournot equilibrium. As a consequence, the private firm's profits are smaller under public leadership than at the Cournot equilibrium, and playing as follower is not an equilibrium for the private firm. The private leadership equilibrium always arises in the SPE given that the public firm prefers to be a follower for the very same reason as in Theorem 13.

\section{Conclusion}

This paper has provided a thorough investigation of the possible endogenous timing outcomes for a mixed duopoly with a foreign or a domestic private firm, under very general specifications of the inverse demand and cost structures. Our main result is that (simultaneous-move) Cournot equilibrium never arises in the endogenous timing equilibrium of the mixed duopoly game (as long as both firms produce positive quantities at equilibrium). When quantities are strategic substitutes for both firms, the two Stackelberg equilibria arise as the only SPEs of the endogenous timing game, irrespective of whether the private firm is foreign or domestic. In this case, the timing scheme invoked here does not allow one to unambiguously assign leader and follower roles to the two firms. When either the public or the private firm has upward sloping best responses, then the endogenous timing scheme yields sequential play as the unique equilibrium with that firm as the leader.

Using the natural and simple endogenous time scheme of Hamilton and Slutsky (1990), our results provide a justification to the use of the Stackelberg concept of equilibrium in mixed duopolies. The striking difference between the result obtained in a mixed duopoly and in a standard private duopoly is primarily explained by the fact that the objective function of a public firm is generally increasing in the rival's output, while the opposite is true for a private firm. In contrast to the concensus that has crystallized around the lack of economic justification for sequential moves in classical quantity oligopoly, the emergence of sequential play as the natural timing for a mixed duopoly suggests a new opportunity to view Stackelberg's classical proposal as being appropriate in some oligopoly settings including a public firm.

If we couple this claim with the results in the private duopoly framework provided by Amir and Grilo (1999), where the Cournot solution is the general outcome, we gain new insights on the effect of privatization (here viewed simply as a change of status of a firm, from public to private). The change in the objective of the former public firm is not the sole effect of privatization. In fact, when it is more reasonable to assume that firms choose not 
only what action to take, but also when to take them, also the timing of the game changes. Since the Stackelberg equilibria dominates Cournot solutions in terms of social welfare, any positive effects of privatization that might be derived under the assumption of Cournot-Nash equilibrium of the game would be overstated and might require revisiting if sequential play is a realistic alternative.

\section{Appendix}

The Appendix includes most of the proofs of the paper but also some intermediate results that are needed for the proof of the main theorems of the paper.

Proof of Lemma 4. A sufficient condition to have $W^{f}\left(q_{0}, q_{1}\right)$ strictly supermodular (strict submodular) is $\frac{\partial^{2} W^{f}\left(q_{0}, q_{1}\right)}{\partial q_{0} \partial q_{1}}>(<) 0$. By the strengthening of Topkis's Theorem given in Amir (1996b) or Edlin and Shannon (1998), a sufficient condition for every selection of $r_{0}($.$) to$ be strictly increasing (strictly decreasing) whenever it is interior is for $\frac{\partial W^{f}\left(q_{0}, q_{1}\right)}{\partial q_{0}}$ to be strictly increasing (decreasing) in $q_{1}$. The latter condition is in turn implied by $P^{\prime \prime}\left(q_{0}+q_{1}\right)<(>) 0$ since

$$
\frac{\partial^{2} W^{f}\left(q_{0}, q_{1}\right)}{\partial q_{0} \partial q_{1}}=-q_{1} P^{\prime \prime}\left(q_{0}+q_{1}\right)
$$

\section{Proof of Lemma 5.}

a) A sufficient condition for the private firm's objective to have the strict DDP is (see Novshek, 1985)

$$
\frac{\partial^{2} \Pi_{1}\left(q_{0}, q_{1}\right)}{\partial q_{0} \partial q_{1}}=P^{\prime}\left(q_{0}+q_{1}\right)+q_{1} P^{\prime \prime}\left(q_{0}+q_{1}\right)<0, \quad \forall q_{0}, q_{1} \geq 0
$$

which is equivalent to

$$
P^{\prime}(x)+x P^{\prime \prime}(x)<0, \quad \forall x \geq 0
$$

A sufficient condition for the strict dual SSCP is

$$
P(x) P^{\prime \prime}(x)-P^{\prime 2}(x)<0, \quad \forall x \geq 0
$$

as defined in Amir (1996a). If one of these conditions holds, then any selection of the private firm's best-response correspondence is strictly decreasing (Amir, 1996b).

b) Since the production costs of the private firm are zero, its objective is $q_{1} P\left(q_{0}+q_{1}\right)$. Given that $\log P(\cdot)$ is convex by assumption, it follows that the objective is strictly log-supermodular, i.e.

$$
\frac{\partial^{2} \log q_{1} P\left(q_{0}+q_{1}\right)}{\partial q_{0} \partial q_{1}}=\frac{P\left(q_{0}+q_{1}\right) P^{\prime \prime}\left(q_{0}+q_{1}\right)-P^{\prime 2}\left(q_{0}+q_{1}\right)}{P^{2}\left(q_{0}+q_{1}\right)}>0 .
$$


So, every selection of the private firm best-response correspondence is strictly increasing (Amir, 1996b).

Before starting the proof of Theorem 6 we need to establish some intermediate results in the following Lemmas 15, 16, and 17.

Lemma 15 Consider the case of a foreign private firm. Under the assumptions of point (a) in Lemma 5 and if $P^{\prime \prime}(\cdot)>0$, the set $N$ includes a point $\left(\underline{q}_{0}, \bar{q}_{1}\right)$ where the private firm produces its largest Cournot equilibrium output and the public firm produces its smallest output in the set $N$. Then $\left(\underline{q}_{0}, \bar{q}_{1}\right)$ is the Pareto dominant mixed-duopoly Cournot equilibrium.

Proof. Reversing the natural order of the public firm's action set, the set $N$ has a largest Cournot equilibrium in the new order, which is clearly $\left(\underline{q}_{0}, \bar{q}_{1}\right) \cdot{ }^{18}$ We show that this is the most preferred Cournot equilibrium by both private and public firms. Consider any other $\left(\widehat{q}_{0}, \widehat{q}_{1}\right) \in N$ different from $\left(\underline{q}_{0}, \bar{q}_{1}\right)$. By the extremal nature of $\left(\underline{q}_{0}, \bar{q}_{1}\right)$ it follows that $\widehat{q}_{1}<\bar{q}_{1}$ and $\widehat{q}_{0}>\underline{q}_{0}$.

(i) For the private firm the following relation holds:

$$
\Pi_{1}\left(\underline{q}_{0}, \bar{q}_{1}\right) \geq \Pi_{1}\left(\underline{q}_{0}, \widehat{q}_{1}\right)>\Pi_{1}\left(\widehat{q}_{0}, \widehat{q}_{1}\right)
$$

where the first inequality derives from $\bar{q}_{1}$ being best response to $\underline{q}_{0}$, and the second inequality is due to private firm's objective being strictly decreasing in $q_{0}$.

(ii) For the public firm, we have

$$
W^{f}\left(\underline{q}_{0}, \bar{q}_{1}\right) \geq W^{f}\left(\widehat{q}_{0}, \bar{q}_{1}\right)>W^{f}\left(\widehat{q}_{0}, \widehat{q}_{1}\right)
$$

where the first inequality is due to the fact that $\underline{q}_{0}$ is a best response to $\bar{q}_{1}$ and the second derives from $W^{f}$ being strictly increasing in $q_{1}$.

This completes the proof.

Lemma 16 Consider the case of a foreign private firm. Under the assumptions of point (a) in Lemma 5 and $P^{\prime \prime}(\cdot)>0$, the output of the private firm (public firm) in a Stackelberg game under either order of moves is larger (smaller) than in the Pareto-dominant mixed-duopoly Cournot equilibrium.

Proof. We have to distinguish the two cases of (i) private leadership, and (ii) public leadership.

\footnotetext{
${ }^{18}$ See Milgrom and Roberts (1990, Theorem 5).
} 
(i) Suppose, by contradiction, that there exists a point $\left(q_{0}^{f}, q_{1}^{l}\right) \in S_{1}$ such that $q_{1}^{l}<\bar{q}_{1}$. Since both $\left(q_{0}^{f}, q_{1}^{l}\right)$ and $\left(\underline{q}_{0}, \bar{q}_{1}\right)$ lay on $G R r_{0}($.$) , which has only decreasing selections,$ it follows that $q_{0}^{f}>\underline{q}_{0}$. Then

$$
\Pi_{1}\left(\underline{q}_{0}, \bar{q}_{1}\right) \geq \Pi_{1}\left(\underline{q}_{0}, q_{1}^{l}\right)>\Pi_{1}\left(q_{0}^{f}, q_{1}^{l}\right)
$$

where the first inequality is due to $\bar{q}_{1}$ being a best response to $\underline{q}_{0}$ and the second by the fact that $\Pi_{1}$ is strictly decreasing in $q_{0}$. Inequality (11) contradicts the nature of Stackelberg equilibrium and so it is always the case that $q_{1}^{l} \geq \bar{q}_{1}$ and $q_{0}^{f} \leq \underline{q}_{0}$.

(ii) Suppose, by contradiction, that there exists a point $\left(q_{0}^{l}, q_{1}^{f}\right) \in S_{0}$ such that $q_{0}^{l}>\underline{q}_{0}$ and so $q_{1}^{f}<\bar{q}_{1}$. Then, the following inequalities hold:

$$
W^{f}\left(\underline{q}_{0}, \bar{q}_{1}\right) \geq W^{f}\left(q_{0}^{l}, \bar{q}_{1}\right)>W^{f}\left(q_{0}^{l}, q_{1}^{f}\right)
$$

where the first inequality is due to $\underline{q}_{0}$ being best response to $\bar{q}_{1}$ and the second to the fact that $W^{f}($.$) is strictly increasing in q_{1}$. Inequality (12) contradicts the nature of Stackelberg equilibria and so it is always the case that $q_{0}^{l} \leq \underline{q}_{0}$ and $q_{1}^{f} \geq \bar{q}_{1}$.

This completes the proof.

Lemma 17 Under the assumptions of point (a) in Lemma 5 and $P^{\prime \prime}(\cdot)>0$, the payoff of the leader in any Stackelberg equilibrium is strictly larger than in any Cournot equilibrium as long as the Pareto dominant Cournot equilibrium is interior.

Proof. If $\left(\underline{q}_{0}, \bar{q}_{1}\right)$ is interior, the following first-order conditions for private and public firms must hold:

$$
\frac{\partial \Pi_{1}\left(\underline{q}_{0}, \bar{q}_{1}\right)}{\partial q_{1}}=0 ; \quad \frac{\partial W^{i}\left(\underline{q}_{0}, \bar{q}_{1}\right)}{\partial q_{0}}=0 \quad i=d, f
$$

We analyze the two possible Stackelberg games separately again.

(i) With private leadership, the private firm's objective can be shown to be $\Pi_{1}\left(\underline{r}_{0}\left(q_{1}\right), q_{1}\right)$ where $\underline{r}_{0}(\cdot)$ is the minimal selection from the public firm's optimal reaction correspondence (see Amir and Grilo, 1999, for a proof). By the Maximum Theorem, the correspondence $r_{0}$ has a closed graph. Hence, $\underline{r}_{0}$ is lower semi-continous and right-continuous (for a proof, see Amir, 1996b). Since $\Pi_{1}$ is decreasing in its first argument and $\underline{r}_{0}$ is decreasing and right-continuous, $\Pi_{1}\left(\underline{r}_{0}\left(q_{1}^{l}\right), q_{1}^{l}\right)$ can have only upward jumps in $q_{1}$ (and no 
downward jumps) and is right-continuous in $q_{1}$. Hence, if $\left(q_{0}^{f}, q_{1}^{l}\right) \in S_{1}$ is also interior, then the following first-order condition for the private leader must hold

$$
\frac{\partial \Pi_{1}\left(q_{0}^{f}, q_{1}^{l}\right)}{\partial q_{1}}+\frac{\partial \Pi_{1}\left(q_{0}^{f}, q_{1}^{l}\right)}{\partial q_{0}} r_{0}^{\prime}\left(q_{1}^{l}\right) \leq 0
$$

where $r_{0}^{\prime}\left(q_{1}^{l}\right)$ is a right Dini derivate. ${ }^{19}$ Since $\frac{\partial \Pi_{1}\left(\underline{q}_{0} \bar{q}_{1}\right)}{\partial q_{0}}<0$ by equation (5), and $\underline{r}_{0}^{\prime}\left(q_{1}^{l}\right)=$ $-\frac{\partial^{2} W^{i}\left(\underline{q}_{0}, \bar{q}_{1}\right) / \partial q_{0} \partial q_{1}}{\partial^{2} W^{i}\left(\underline{q}_{0}, \bar{q}_{1}\right) / \partial q_{0}^{2}}<0$ whenever $\underline{r}_{0}$ is interior by point (a) of Lemma 4 , it follows from (13) that $\frac{\partial \Pi_{1}\left(q_{0}^{f}, q_{1}^{l}\right)}{\partial q_{1}}<0$ at any interior point. Hence, $\left(\underline{q}_{0}, \bar{q}_{1}\right) \notin S_{1}$, and $q_{1}^{l}>\bar{q}_{1}$ and $q_{0}^{f}<\underline{q}_{0}$.

If $\left(q_{0}^{f}, q_{1}^{l}\right)$ is not interior, then the conclusion follows from the interiority of $\left(\underline{q}_{0}, \bar{q}_{1}\right)$.

(ii) With public leadership, the public firm's objective can be shown to be $W^{i}\left(q_{0}, \bar{r}_{1}\left(q_{0}\right)\right)$ where $\bar{r}_{1}(\cdot)$ is the maximal selection from the public firm's optimal reaction correspondence (see Amir and Grilo, 1999, for a proof). Since the point $\left(q_{0}^{l}, q_{1}^{f}\right)$ lies on $\bar{r}_{1}(\cdot)$, the following first-order condition of the private firm holds:

$$
P\left(q_{0}+\bar{r}_{1}\left(q_{0}\right)\right)+\bar{r}_{1}\left(q_{0}\right) P^{\prime}\left(q_{0}+\bar{r}_{1}\left(q_{0}\right)\right)-C_{1}^{\prime}\left(\bar{r}_{1}\left(q_{0}\right)\right)=0
$$

Then, at $\left(q_{0}^{l}, q_{1}^{f}\right)$, price is strictly above the private firm's marginal cost and it follows that $\frac{\partial W^{i}\left(q_{0}^{l}, q_{1}^{f}\right)}{\partial q_{1}}>0$. Using also the fact that $\bar{r}_{1}$ is decreasing and left-continuous (as in Part (i)), we know that $W^{i}\left(q_{0}, \bar{r}_{1}\left(q_{0}\right)\right)$ can have only downward jumps in $q_{0}$ (and no upward jumps) and is left-continuous in $q_{0}$. Hence, if $\left(q_{0}^{l}, q_{1}^{f}\right) \in S_{0}$ is interior, the following first-order condition for the public leader must hold (here, $r_{1}^{\prime}\left(q_{0}^{l}\right)$ is a left Dini derivate)

$$
\frac{\partial W^{i}\left(q_{0}^{l}, q_{1}^{f}\right)}{\partial q_{0}}+\frac{\partial W^{i}\left(q_{0}^{l}, q_{1}^{f}\right)}{\partial q_{1}} r_{1}^{\prime}\left(q_{0}^{l}\right) \geq 0, \quad i=f, d .
$$

Since $\left(q_{0}^{l}, q_{1}^{f}\right)$ is interior, we have $r_{1}^{\prime}\left(q_{0}^{l}\right)<0$ via an argument similar to the analogous step in part (i). Then (14) implies that $\frac{\partial W^{i}\left(q_{0}^{l}, q_{1}^{f}\right)}{\partial q_{0}}>0$. This implies that $\left(\underline{q}_{0}, \bar{q}_{1}\right) \notin S_{0}$. Therefore $q_{0}^{l}<\underline{q}_{0}$ and $q_{1}^{f}>\bar{q}_{1}$.

If $\left(q_{0}^{l}, q_{1}^{f}\right)$ is not interior, then the conclusion follows from the interiority of $\left(\underline{q}_{0}, \bar{q}_{1}\right)$.

\footnotetext{
${ }^{19}$ The four Dini derivates are the lim sup and lim inf of the one-sided (left and right) directional slopes starting at any point and always exist in the extended reals.
} 
This completes the proof.

Proof of Theorem 6. In Lemma 15 we have shown that the point $\left(\underline{q}_{0}, \bar{q}_{1}\right)$ is the most preferred simultaneous-move equilibrium by both firms. Moreover, by Lemmas 16-17, any $\left(q_{0}^{f}, q_{1}^{l}\right) \in S_{1}$ is such that $q_{1}^{l}>\bar{q}_{1}$ and $q_{0}^{f}<\underline{q}_{0}$, and any $\left(q_{0}^{l}, q_{1}^{f}\right) \in S_{0}$ is such that $q_{1}^{f}>\bar{q}_{1}$ and $q_{0}^{l}<\underline{q}_{0}$. Now we show that each firm strictly prefers being a follower in a sequential-move game to the Pareto dominant Cournot equilibrium.

For the private firm, the following relation holds

$$
\Pi_{1}\left(q_{0}^{l}, q_{1}^{f}\right) \geq \Pi_{1}\left(q_{0}^{l}, \bar{q}_{1}\right)>\Pi_{1}\left(\underline{q}_{0}, \bar{q}_{1}\right)
$$

where the first inequality comes from the fact that $q_{1}^{f}$ is a best response to $q_{0}^{l}$ and the second is due to the private firm's objective being strictly decreasing in $q_{0}$.

For the public firm the following relation holds:

$$
W^{f}\left(q_{0}^{f}, q_{1}^{l}\right) \geq W^{f}\left(\underline{q}_{0}, q_{1}^{l}\right)>W^{f}\left(\underline{q}_{0}, \bar{q}_{1}\right)
$$

where the first inequality is due to $q_{0}^{f}$ being a best response to $q_{1}^{l}$, and the second derives from the fact that $W$ is strictly increasing in $q_{1}$.

Then, the conditions of point (ii) of Proposition 3 hold and both Stackelberg equilibria are SPEs of the endogenous timing game.

Proof of Theorem 10. By strict quasi-concavity of both objectives, the reaction correspondences of both firms are (single-valued) continuous functions. Moreover the reaction correspondence of the public firm is strictly decreasing when interior. Hence, the mixed duopoly Cournot equilibrium $\left(\underline{q}_{0}, \bar{q}_{1}\right)$ is unique. We now prove that: (i) the public firm is better off in the private leadership than in the mixed-duopoly Cournot equilibrium; while (ii) the private firm's payoff is strictly larger in the Cournot than in the public leadership equilibrium.

(i) For the private leadership equilibrium, since $r_{0}$ is strictly decreasing in the interior, we can apply the same analysis as in point $(i)$ in Lemmas 16-17 to show that $q_{1}^{l}>\bar{q}_{1}$ and $q_{0}^{f}<\underline{q}_{0}$. It follows that:

$$
W^{f}\left(q_{0}^{f}, q_{1}^{l}\right) \geq W^{f}\left(\underline{q_{0}}, q_{1}^{l}\right)>W^{f}\left(\underline{q_{0}}, \overline{q_{1}}\right)
$$

where the first inequality is due to $q_{0}^{f}$ being best response to $q_{1}^{l}$, and the second derives from the fact that $W_{f}$ is strictly increasing in $q_{1}$. 
(ii) We now analyze the public firm's leadership equilibrium. First we show that the Stackelberg equilibrium $\left(q_{0}^{l}, q_{1}^{f}\right) \in S_{0}$ is such that $q_{0}^{l}>\underline{q_{0}}$ and $q_{1}^{f}>\overline{q_{1}}$. Suppose by contradiction that $q_{0}^{l}<\underline{q_{0}}$. Since $r_{1}$ is strictly increasing when interior, it follows that $q_{1}^{f}<\overline{q_{1}}$. Then,

$$
W^{f}\left(\underline{q_{0}}, \overline{q_{1}}\right) \geq W^{f}\left(q_{0}^{l}, \overline{q_{1}}\right)>W^{f}\left(q_{0}^{l}, q_{1}^{f}\right)
$$

where the first inequality comes from $\underline{q_{0}}$ being a best response to $\overline{q_{1}}$ and the second is due to $W^{f}\left(q_{0}, q_{1}\right)$ being strictly increasing in $q_{1}$. Therefore $q_{0}^{l} \geq \underline{q_{0}}$. Moreover, by an argument analogous to the one used in point $(i)$ of the proof of Lemma $17,\left(\underline{q}_{0}, \bar{q}_{1}\right) \notin S_{0}$ and therefore $q_{0}^{l}>\underline{q}_{0}$. Since $r_{1}$ is strictly increasing in the interior it follows that $q_{1}^{f}>\bar{q}_{1}$. As a consequence, we can rank the private firm's payoffs in the following way:

$$
\Pi_{1}\left(\underline{q}_{0}, \bar{q}_{1}\right) \geq \Pi_{1}\left(\underline{q}_{0}, q_{1}^{f}\right)>\Pi_{1}\left(q_{0}^{l}, q_{1}^{f}\right)
$$

where the first inequality follows from the property of Cournot equilibria and the second from the fact that $\Pi_{1}$ is strictly decreasing in $q_{0}$. Then, the private firm strictly prefers Cournot to public leadership equilibria.

The conditions of point iii) of Proposition 3 hold and the private leadership equilibrium is the unique SPE of the endogenous timing game.

Proof of Theorem 11. By the strict quasi-concavity of both $W^{f}($.$) and \Pi_{1}(),. r_{0}\left(q_{1}\right)$ and $r_{1}\left(q_{0}\right)$ are single-valued continuous functions. Moreover, $r_{0}\left(q_{1}\right)$ is strictly increasing and $r_{1}\left(q_{0}\right)$ is strictly decreasing in the interior. Hence, there exists a unique Cournot equilibrium, which thus coincides with $\left(\underline{q}_{0}, \bar{q}_{1}\right)$. We now prove that: (i) the public firm's payoff is strictly larger in the Cournot equilibrium that in the private leadership equilibrium; while (ii) the private firm is better off in the public leadership equilibrium than in the Cournot equilibrium.

(i) First we show that the private leadership equilibrium is such that $q_{1}^{l}<\bar{q}_{1}$ and $q_{0}^{f}<\underline{q}_{0}$. Suppose by contradiction that $q_{1}^{l}>\bar{q}_{1}$; since $r_{0}$ is strictly increasing in the interior $q_{0}^{f}>\underline{q}_{0}$. It follows that

$$
\Pi_{1}\left(\underline{q_{0}}, \overline{q_{1}}\right) \geq \Pi_{1}\left(\underline{q_{0}}, q_{1}^{l}\right)>\Pi_{1}\left(q_{0}^{f}, q_{1}^{l}\right)
$$

where the first inequality is due to $\overline{q_{1}}$ being a best response to $\underline{q_{0}}$, and the second derives from the fact that $\Pi_{1}\left(q_{0}, q_{1}\right)$ is strictly decreasing in $q_{0}$. Therefore $q_{1}^{l} \leq \bar{q}_{1}$ and $q_{0}^{f} \leq \underline{q}_{0}$. By an argument analogous to the one in point $(i)$ of the proof of Lemma $17,\left(\underline{q_{0}}, \overline{q_{1}}\right) \notin S_{1}$ and therefore $q_{1}^{l}<\bar{q}_{1}$ and $q_{0}^{f}<\underline{q}_{0}$.

We can show that

$$
W^{f}\left(\underline{q_{0}}, \overline{q_{1}}\right) \geq W^{f}\left(q_{0}^{f}, \overline{q_{1}}\right)>W^{f}\left(q_{0}^{f}, q_{1}^{l}\right)
$$


where the first inequality is due to $\underline{q}_{0}$ being best response to $\overline{q_{1}}$ and the second to $W^{f}\left(q_{0}, q_{1}\right)$ being strictly increasing in $q_{1}$.

(ii) From the interiority of $\left(\underline{q}_{0}, \bar{q}_{1}\right)$ and since $r_{1}$ is strictly decreasing in the interior we can apply the same analysis as point $(i i)$ in the proof of Lemma 16 to show that $q_{0}^{l} \leq \underline{q_{0}}$ and $q_{1}^{f} \geq \overline{q_{1}}$. Moreover, by point (ii) in the proof of Lemma $17,\left(\underline{q_{0}}, \overline{q_{1}}\right) \notin S_{0}$ and therefore $q_{0}^{l}<\underline{q_{0}}$ and $q_{1}^{f}>\overline{q_{1}}$.

It follows that

$$
\Pi_{1}\left(q_{0}^{l}, q_{1}^{f}\right) \geq \Pi_{1}\left(q_{0}^{l}, \overline{q_{1}}\right)>\Pi_{1}\left(\underline{q_{0}}, \overline{q_{1}}\right)
$$

where the first inequality follows from the fact that $q_{1}^{f}$ is a best response to $q_{0}^{l}$ and the second from the fact that $\Pi_{1}\left(q_{0}, q_{1}\right)$ is strictly decreasing in $q_{0}$. Then, the private firm strictly prefers public leadership to the best Cournot equilibrium.

The conditions of point iii) of Proposition 3 hold and public leadership is the unique SPE of the endogenous timing game.

Proof of Lemma 12. Since the public firm maximizes total welfare as defined in equation (1), its objective has DDP since

$$
\frac{\partial^{2} W^{d}\left(q_{0}, q_{1}\right)}{\partial q_{0} \partial q_{1}}=P^{\prime}\left(q_{0}+q_{1}\right)<0 \quad \forall q_{0}, q_{1} \geq 0 .
$$

So, under the standard assumptions, any selection of the best-response correspondence of the public firm is strictly decreasing.

In order to prove Theorem 13, we need to establish some intermediate results in the following Lemmas 18 and 19.

Lemma 18 Consider the case of a domestic private firm. A sufficient condition for the extremal equilibrium $\left(\underline{q}_{0}, \bar{q}_{1}\right)$ to be the Pareto dominant mixed-duopoly Cournot equilibrium is that the public firm's cost function is convex in the relevant range.

Proof. As in Lemma 15, since both reaction correspondence are strictly decreasing in the interior, $\left(\underline{q}_{0}, \bar{q}_{1}\right)$ is the extremal point in $N$ and any other $\left(\widehat{q}_{0}, \widehat{q}_{1}\right) \in N$ distinct from $\left(\underline{q}_{0}, \bar{q}_{1}\right)$ is such that $\widehat{q}_{1}<\bar{q}_{1}$ and $\widehat{q}_{0}>\underline{q}_{0}$.

(i) For the private firm, we have that $\Pi_{1}\left(\underline{q}_{0}, \bar{q}_{1}\right)>\Pi_{1}\left(\widehat{q}_{0}, \widehat{q}_{1}\right)$, as shown in Lemma 15 by the inequality chain (9); 
(ii) For the public firm, we first show that the slopes of $r_{0}\left(q_{1}\right)$ are all in $[-1,0)$. To this end, consider the change of variable $x=q_{0}+q_{1}$ and view $x$ as the new decision variable for the public firm in the modified objective

$$
\max _{x \geq 0} \int_{0}^{x} P(t) d t-C_{0}\left(x-q_{1}\right)-C_{1}\left(q_{1}\right)
$$

Since the cross-partial of this objective w.r.t. $x$ and $q_{1}$ is equal to $C_{0}^{\prime \prime}\left(x-q_{1}\right) \geq 0$ by the convexity assumption, we conclude that the $\operatorname{argmax} x^{*}\left(q_{1}\right)$ is increasing in $q_{1}$ (note here that $x^{*}\left(q_{1}\right)$ is single-valued since $W^{d}$ is strictly concave in $\left.q_{0}\right)$. Since $x^{*}\left(q_{1}\right)=r_{0}\left(q_{1}\right)+q_{1}$, we conclude that the slopes of $r_{0}\left(q_{1}\right)$ are all $\geq-1$. A standard application of the smooth Implicit Function Theorem shows that $r_{0}^{\prime}\left(q_{1}\right) \geq-1$.

The next step is to note that given that both $\left(\widehat{q}_{0}, \widehat{q}_{1}\right)$ and $\left(\underline{q}_{0}, \bar{q}_{1}\right)$ lie on $G R r_{0}\left(q_{1}\right)$, it follows that ${ }^{20}$

$$
W^{d}\left(\underline{q}_{0}, \bar{q}_{1}\right)-W^{d}\left(\widehat{q}_{0}, \widehat{q}_{1}\right)=\int_{\widehat{q}_{1}}^{\bar{q}_{1}} \frac{d W^{d}\left(r_{0}\left(q_{1}\right), q_{1}\right)}{d q_{1}} d q_{1}=\int_{\widehat{q}_{1}}^{\bar{q}_{1}} \frac{\partial W^{d}\left(r_{0}\left(q_{1}\right), q_{1}\right)}{\partial q_{1}} d q_{1}
$$

where the latter equality derives from the application of the Envelope Theorem. Hence,

$$
\begin{aligned}
\frac{\partial W^{d}\left(r_{0}\left(q_{1}\right), q_{1}\right)}{\partial q_{1}} & =P\left(r_{0}\left(q_{1}\right)+q_{1}\right)-C_{1}^{\prime}\left(q_{1}\right) \\
& \geq P\left(r_{0}\left(q_{1}\right)+q_{1}\right)-C_{1}^{\prime}\left(q_{1}\right)+\left[1+r_{0}^{\prime}\left(q_{1}\right)\right] q_{1} P^{\prime}\left(r_{0}\left(q_{1}\right)+q_{1}\right) \\
& =\frac{d \Pi_{1}\left(r_{0}\left(q_{1}\right), q_{1}\right)}{d q_{1}}
\end{aligned}
$$

where the inequality follows from the fact that $-1 \leq r_{0}^{\prime}\left(q_{1}\right) \leq 0, \forall q_{1} \geq 0$.

Then:

$$
\int_{\widehat{q}_{1}}^{\bar{q}_{1}} \frac{d W^{d}\left(r_{0}\left(q_{1}\right), q_{1}\right)}{d q_{1}} d q_{1} \geq \int_{\widehat{q}_{1}}^{\bar{q}_{1}} \frac{d \Pi_{1}\left(r_{0}\left(q_{1}\right), q_{1}\right)}{d q_{1}} d q_{1}=\Pi_{1}\left(\underline{q}_{0}, \bar{q}_{1}\right)-\Pi_{1}\left(\widehat{q}_{0}, \widehat{q}_{1}\right)>0
$$

where the latter inequality comes from the result in point (i).

This completes the proof. ${ }^{21}$

\footnotetext{
${ }^{20} G R$ stays for the graph of the best-reply function $r_{i}(\cdot)$.

${ }^{21}$ Note that this result has the obvious extension that all the mixed duopoly Cournot equilibria can be Pareto ranked from the smallest to the largest in the reversed order. A similar result is obtained by Milgrom and Roberts (1990, Theorem 7) for 2-player supermodular games when both objectives are monotonic in the rival's action. Since the public firm's objective has not this property, we have developed a novel methodology to make comparative statics in the framework of a (domestic) mixed duopoly.
} 
Lemma 19 Consider the case of a domestic private firm. In addition to the assumptions in Lemma 5(a), assume that the public firm's cost function is convex. Then, the output of the private firm (public firm) in any Stackelberg game with both orders of moves is strictly larger (strictly smaller) than in the Pareto-dominant mixed duopoly Cournot equilibrium.

Proof. We distinguish the two cases of (i) private leadership, and (ii) public leadership.

(i) The case of private leadership has been already discussed in Lemmas 16-17 where it is shown that $q_{1}^{l}>\bar{q}_{1}$ and $q_{0}^{f}<\underline{q}_{0}$ always, and $\left(\underline{q}_{0}, \bar{q}_{1}\right) \notin S_{1}$.

(ii) The case of public leadership is instead different since $W^{d}$ is not always increasing in $q_{1}$. We need therefore a different proof. Suppose by contradiction that $q_{1}^{l}<\bar{q}_{1}$.

First observe that, since $r_{0}\left(q_{1}^{f}\right)$ is a best response,

$$
W^{d}\left(q_{0}^{l}, q_{1}^{f}\right) \leq W^{d}\left(r_{0}\left(q_{1}^{f}\right), q_{1}^{f}\right) .
$$

Moreover, given that both $\left(r_{0}\left(q_{1}^{f}\right), q_{1}^{f}\right)$ and $\left(\underline{q}_{0}, \bar{q}_{1}\right)$ lay on $G R r_{0}($.$) , we can apply the$ envelope theorem as in equation (15) and obtain the following relation between welfare and profits

$$
W^{d}\left(\underline{q}_{0}, \bar{q}_{1}\right)-W^{d}\left(r_{0}\left(q_{1}^{f}\right), q_{1}^{f}\right) \geq \Pi_{1}\left(\underline{q}_{0}, \bar{q}_{1}\right)-\Pi_{1}\left(r_{0}\left(q_{1}^{f}\right), q_{1}^{f}\right)>0
$$

(17) comes from the fact that

$$
\Pi_{1}\left(\underline{q}_{0}, \bar{q}_{1}\right) \geq \Pi_{1}\left(\underline{q}_{0}, q_{1}^{f}\right)>\Pi_{1}\left(r_{0}\left(q_{1}^{f}\right), q_{1}^{f}\right)
$$

where the first inequality comes from $\bar{q}_{1}$ being a best response to $\underline{q}_{0}$, and the second is due to the fact that $\Pi_{1}($.$) is strictly decreasing in q_{0}$ and $r_{0}\left(q_{1}^{f}\right)>\underline{q}_{0} \cdot{ }^{22}$ So, combining inequalities (16) and (17), whenever $q_{1}^{f}<\bar{q}_{1}$, the following relation holds

$$
W^{d}\left(q_{0}^{l}, q_{1}^{f}\right) \leq W^{d}\left(r_{0}\left(q_{1}^{f}\right), q_{1}^{f}\right)<W^{d}\left(\underline{q}_{0}, \bar{q}_{1}\right),
$$

which contradicts the nature of Stackelberg equilibrium. Therefore, it must be that $q_{1}^{f} \geq \bar{q}_{1}$ and $q_{0}^{l} \leq \underline{q}_{0}$.

Moreover, we can apply the result in point $(i i)$ of the proof of Lemma 17 to show that $\left(\underline{q}_{0}, \bar{q}_{1}\right) \notin S_{0}$ and to conclude that the inequalities are strict, i.e., $q_{1}^{f}>\bar{q}_{1}$ and $q_{0}^{l}<\underline{q}_{0}$.

\footnotetext{
${ }^{22}$ Since both $\left(r_{0}\left(q_{1}^{f}\right), q_{1}^{f}\right)$ and $\left(\underline{q}_{0}, \bar{q}_{1}\right)$ lay on $G R r_{0}($.$) and given the contradiction hypothesis that q_{1}^{f}<\bar{q}_{1}$, it follows that $r_{0}\left(q_{1}^{f}\right)>\underline{q}_{0}$ because any selection of $r_{0}($.$) is strictly decreasing.$
} 
This completes the proof.

Proof of Theorem 13. To prove this result we need to show that both firms prefer the follower outcome to any simultaneous play solution whenever the Pareto dominant Cournot equilibrium $\left(\underline{q}_{0}, \bar{q}_{1}\right)$ is interior.

(i) By point (i) of Lemma 19 we know that any $\left(q_{0}^{f}, q_{1}^{l}\right) \in S_{1}$ is such that $q_{0}^{f}<\underline{q}_{0}$ and $q_{1}^{l}>\bar{q}_{1}$. Moreover, from the definitions of Cournot and Stackelberg equilibria, both $\left(q_{0}^{f}, q_{1}^{l}\right)$ and $\left(\underline{q}_{0}, \bar{q}_{1}\right)$ lay on $G R r_{0}\left(q_{1}\right)$. Then, as in proof of Lemma 18, we can apply the Envelope Theorem and obtain the following relation between welfare and profits:

$$
W^{d}\left(q_{0}^{f}, q_{1}^{l}\right)-W^{d}\left(\underline{q}_{0}, \bar{q}_{1}\right) \geq \Pi_{1}\left(q_{0}^{f}, q_{1}^{l}\right)-\Pi_{1}\left(\underline{q}_{0}, \bar{q}_{1}\right)>0
$$

where the latter inequality comes from the property of Stackelberg equilibria, and it is strict by the result in point $(i)$ of the proof of Lemma 17 .

(ii) By point (ii) of Lemma 19, we know that any $\left(q_{0}^{l}, q_{1}^{f}\right) \in S_{0}$ is such that $q_{0}^{l}<\underline{q}_{0}$ and $q_{1}^{f}>\bar{q}_{1}$. Then it follows that

$$
\Pi_{1}\left(q_{0}^{l}, q_{1}^{f}\right) \geq \Pi_{1}\left(q_{0}^{l}, \bar{q}_{1}\right)>\Pi_{1}\left(\underline{q}_{0}, \bar{q}_{1}\right)
$$

where the first inequality comes from the fact that $q_{1}^{f}$ is best response to $q_{0}^{l}$ and the second is due to the private firm's objective being strictly decreasing in $q_{0}$.

The conditions of point (ii) of Proposition 3 hold and both Stackelberg equilibria are SPE of the endogenous timing game.

Proof of Theorem 14. by Point (b) in Lemma 5 any selection of the best response correspondence $r_{1}\left(q_{0}\right)$ is strictly increasing in the interior. By point (a) of Lemma $9 r_{1}\left(q_{0}\right)$ is single valued and continuous. Since $C_{0}$ is convex, $r_{0}\left(q_{1}\right)$ is single valued, continuous, and decreasing when interior. Hence, the mixed duopoly Cournot equilibrium $\left(\underline{q}_{0}, \bar{q}_{1}\right)$ is unique. As in the proof of Theorem 11, we now prove that: (i) the public firm is better off in the private leadership than in the mixed-duopoly Cournot equilibrium; while (ii) the private firm's payoff is strictly larger in the Cournot than in the public leadership equilibrium.

(i) For the private leadership equilibrium, since $r_{0}$ is strictly decreasing in the interior, we can apply the same analysis as in point $(i)$ in Theorem 13 to show that from inequality (18) it follows that

$$
W^{d}\left(q_{0}^{f}, q_{1}^{l}\right)>W^{d}\left(\underline{q}_{0}, \bar{q}_{1}\right)
$$


(ii) We now analyze the public firm's leadership equilibrium. We first show the public leadership equilibrium $\left(q_{0}^{l}, q_{1}^{f}\right) \in S_{0}$ is such that $q_{0}^{l}>\underline{q_{0}}$ and $q_{1}^{f}>\overline{q_{1}}$. Suppose by contradiction that $q_{0}^{l}<\underline{q_{0}}$. First observe that

$$
W^{d}\left(q_{0}^{l}, q_{1}^{f}\right) \leq W^{d}\left(r_{0}\left(q_{1}^{f}\right), q_{1}^{f}\right)
$$

because $r_{0}\left(q_{1}^{f}\right)$ is a best response. Moreover, given that both $\left(r_{0}\left(q_{1}^{f}\right), q_{1}^{f}\right)$ and $\left(\underline{q_{0}}, \overline{q_{1}}\right)$ lay on $G R r_{0}$ (.) with $q_{1}^{F}<\overline{q_{1}}$, we can apply the envelope theorem as in equation (15) to show that

$$
W^{d}\left(\underline{q_{0}}, \overline{q_{1}}\right)-W^{d}\left(r_{0}\left(q_{1}^{f}\right), q_{1}^{f}\right) \geq \Pi_{1}\left(\underline{q_{0}}, \overline{q_{1}}\right)-\Pi_{1}\left(r_{0}\left(q_{1}^{f}\right), q_{1}^{f}\right)>0
$$

The latter inequality comes from the fact that

$$
\Pi_{1}\left(\underline{q_{0}}, \overline{q_{1}}\right) \geq \Pi_{1}\left(\underline{q_{0}}, q_{1}^{f}\right)>\Pi_{1}\left(r_{0}\left(q_{1}^{f}\right), q_{1}^{f}\right)
$$

where the first inequality comes from $\bar{q}_{1}$ being a best response to $\underline{q}_{0}$, and the second is due to the fact that $\Pi_{1}($.$) is strictly decreasing in q_{0}$ and $r_{0}\left(q_{1}^{f}\right)>\underline{q_{0}}$. Considering the two inequalities (20) and (21), it follows that

$$
W^{d}\left(q_{0}^{l}, q_{1}^{f}\right) \leq W^{d}\left(r_{0}\left(q_{1}^{f}\right), q_{1}^{f}\right)<W^{d}\left(\underline{q_{0}}, \overline{q_{1}}\right)
$$

which contradicts the nature of Stackelberg equilibrium. Therefore it must be that $q_{0}^{l} \geq \underline{q_{0}}$ and $q_{1}^{f} \geq \overline{q_{1}}$. Moreover, we can apply the result in point (ii) of the proof of Lemma 17 to show that $\left(\underline{q}_{0}, \bar{q}_{1}\right) \notin S_{0}$ and to conclude that the inequalities are strict.

So, since the Stackelberg equilibrium $\left(q_{0}^{l}, q_{1}^{f}\right) \in S_{0}$ is such that $q_{0}^{l}>\underline{q_{0}}$ and $q_{1}^{f}>\overline{q_{1}}$, then

$$
\Pi_{1}\left(\underline{q_{0}}, \overline{q_{1}}\right) \geq \Pi_{1}\left(\underline{q_{0}}, q_{1}^{f}\right)>\Pi_{1}\left(q_{0}^{l}, q_{1}^{f}\right)
$$

where the first inequality follows from the property of Cournot equilibria and the second from the fact that $\Pi_{1}$ is strictly decreasing in $q_{0}$. Then, the private firm strictly prefers Cournot to public leadership equilibria.

Therefore the conditions of point iii) of Proposition 3 hold and the private leadership equilibrium is the unique SPE of the endogenous timing game. 


\section{References}

Amir, Rabah, "Endogenous Timing in Two-Player Games: A Counterexample," Games and Economic Behavior, May 1995, 9 (2), 234-237.

_ , "Cournot Oligopoly and the Theory of Supermodular Games," Games and Economic Behavior, August 1996, 15 (2), 132-148.

_ , "Sensitivity analysis of multisector optimal economic dynamics," Journal of Mathematical Economics, January 1996, 25 (1), 123-141.

- and Isabel Grilo, "Stackelberg versus Cournot Equilibrium," Games and Economic Behavior, January 1999, 26 (1), 1-21.

Barros, Fátima, "Incentive schemes as strategic variables: An application to a mixed duopoly," International Journal of Industrial Organization, September 1995, 13 (3), 373386 .

Beato, Paulina and Andreu Mas-Colell, "The Marginal Cost Pricing Rule as a Regulation Mechanism in Mixed Markets," in Maurice Marchand, Pierre Pestieu, and Henry Tulkens, eds., The Performance of Public Enterprises, Vol. 33 of Studies in Mathematical and Managerial Economics, Amsterdam, NL: Elsevier Science B.V., January 1984, pp. 81100.

Bös, Dieter, Public Enterprise Economics: Theory and Applications, 2nd ed., Vol. 23 of Advanced Textbooks in Economics, Amsterdam, NL: North Holland, January 1986.

Cornes, Richard C. and Mehrdad Sepahvand, "Cournot Vs Stackelberg Equilibria with a Public Enterprise and International Competition," Economics Discussion Paper 12, University of Nottingham July 2003.

Cremer, Helmuth, Maurice Marchand, and Jacques-François Thisse, "The Public Firm as an Instrument for Regulating an Oligopolistic Market," Oxford Economic Papers, April 1989, 41 (2), 283-301.

de Fraja, Giovanni and Flavio Delbono, "Alternative Strategies of a Public Enterprise in Oligopoly," Oxford Economic Papers, April 1989, 41 (2), 302-311.

_ and _ , "Game Theoretic Models of Mixed Oligopoly," Journal of Economic Surveys, March 1990, 4 (1), 1-17.

Edlin, Aaron S. and Chris Shannon, "Strict Monotonicity in Comparative Statics,," Journal of Economic Theory, 7 1998, 81 (1), 201-219. 
Fjell, Kenneth and Debashis Pal, "A mixed oligopoly in the presence of foreign private firms," Canadian Journal of Economics, August 1996, 29 (3), 737-743.

- and John S. Heywood, "Public Stackelberg Leadership in a Mixed Oligopoly with Foreign Firms," Australian Economic Papers, September 2002, 41 (3), 267-281.

Hamilton, Jonathan H. and Steven M. Slutsky, "Endogenous timing in duopoly games: Stackelberg or cournot equilibria," Games and Economic Behavior, March 1990, 2 (1), 29 46 .

Hellwig, Martin and Wolfgang Leininger, "On the existence of subgame-perfect equilibrium in infinite-action games of perfect information," Journal of Economic Theory, October 1987, 43 (1), 55-75.

Lipsey, Richard G. and Kelvin Lancaster, "The General Theory of Second Best," The Review of Economic Studies, 1956-1957, 24 (1), 11-32.

Magnus, Eivind G.B. and Atle Midttun, "The Norwegian Model: Competitive Public Economy," in Eivind G.B. Magnus and Atle Midtun, eds., Electricity Market Reform in Norway, London, UK: Palgrave Macmillan, May 2000.

Matsumura, Toshihiro, "Stackelberg Mixed Duopoly with a Foreign Competitor," Bulletin of Economic Research, July 2003, 55 (3), 275-287.

Milgrom, Paul and Chris Shannon, "Monotone Comparative Statics," Econometrica, January 1994, 62 (1), 157-180.

- and John Roberts, "Rationalizability, learning, and equilibrium in games with strategic complementarities," Econometrica, November 1990, 58 (6), 1255-1277.

Nett, Lorenz, "Mixed Oligopoly with Homogeneous Goods," Annals of Public and Cooperative Economics, July 1993, 64 (3), 367-393.

Novshek, William, "On the Existence of Cournot Equilibrium," Review of Economic Studies, January 1985, 52 (168), 85-98.

Pal, Debashis, "Endogenous timing in a mixed oligopoly," Economics Letters, November 1998, 61 (2), 181-185.

- and Mark D. White, "Mixed Oligopoly, Privatization, and Strategic Trade Policy," Southern Economic Journal, October 1998, 65 (2), 264-281.

Rees, Ray, Public Enterprise Economics, 2nd ed., London, UK: Palgrave Macmillan, December 1984. 
Sepahvand, Mehrdad, "Public Enterprise Strategies in a Market Open to Domestic and International Competition," Annales d'Économie et de Statistique, July 2004, 75-76, 135153.

Topkis, Donald M., "Minimizing a Submodular Function on a Lattice," Operations Research, March-April 1978, 26 (2), 305-321.

_ , "Equilibrium Points in Nonzero-Sum n-Person Submodular Games," SIAM Journal on Control and Optimization, December 1979, 17 (6), 773-787.

_ , Supermodularity and Complementarity, Princeton, N.J.: Princeton University Press, April 1998.

Vives, Xavier, "Nash equilibrium with strategic complementarities," Journal of Mathematical Economics, July 1990, 19 (3), 305-321.

von Stengel, Bernhard, "Follower payoffs in symmetric duopoly games," Games and Economic Behavior, 7 2010, 69 (2), 512-516.

- and Shmuel Zamir, "Leadership games with convex strategy sets," Games and Economic Behavior, 7 2010, 69 (2), 446-457. 